\title{
VARIATIONS OF N-P-K CONTENTS IN LIVESTOCK AND LIVESTOCK MANURE COMPOSTING
}

\author{
ZHEN, X. F. ${ }^{1 *}-$ LuO, M. ${ }^{1}-$ DONG, H. Y. ${ }^{1}-$ LI, S. B. ${ }^{1}-$ LI, M. C. ${ }^{1}-$ KANG, J. ${ }^{2}$ \\ ${ }^{1}$ School of New Energy and Power Engineering, Lanzhou Jiaotong University \\ Lanzhou 730070, China \\ ${ }^{2}$ School of Material Science and Engineering, Lanzhou University of Technology \\ Lanzhou 730050, China \\ (phone: +86-1391-930-2012) \\ Corresponding author \\ e-mail:zxf283386515@163.com \\ (Received 29 $9^{\text {th }}$ Jul 2020; accepted $19^{\text {th }}$ Nov 2020)
}

\begin{abstract}
In this study, we used three kinds of fresh livestock manure as raw materials and 10\% corn stalks as a leavening agent for aerobic static composting to investigate variations of total nitrogen (TN), ammonia nitrogen (AN), total phosphorus (TP), active phosphorus (AP), total potassium (TK), and active potassium (AK) during the three kinds of livestock and poultry manure composting in China. Results show that the percentage content of TN presented an increasing trend, and the fractions of AN in TN first rose and then declined as the composting proceeded in the compost heaps. The fraction of AN in TN for R1, R2, and R3 reached the peak of 7.38, 8.11, and 9.22\%, respectively. The fraction of AP in TP for R1, R2, and R3 reached $24.15 \pm 1.97,29.33 \pm 3.34$, and $34.33 \pm 1.58 \%$ with the increase of $31.89,18.26$, and $35.53 \%$, respectively, at the end of composting. The fraction of AK in TK for R1, R2, and R3 reached $49.44 \pm 2.74$, $58.37 \pm 2.21$, and $64.25 \pm 3.56 \%$ with the increase of $32.44,35.05$, and $45.32 \%$, respectively, at the end of composting.
\end{abstract}

Keywords: static composting, materials conversion, ammonia nitrogen content, active phosphorus content, compost fertility

\section{Introduction}

With the development of the livestock industry, waste generated by intensive livestock farming poses a lot of serious threats to the natural environment and can pollute water, air, and soil. Taking Lanzhou as an example, with the implementation of the poverty alleviation policy involving the breeding industry in Lanzhou in recent years, the development of the local livestock breeding has been accelerated, and the number and scale of farms have been greatly improved (Zhu et al., 2014; Meng, 2014). With the rapid development of the livestock industry, the pollution caused by livestock manure to the environment cannot be ignored. Recycling and harmless treatment of agricultural waste, such as livestock and poultry manure, will help reduce pollution caused by indiscriminate discharge of livestock manure. In recent years, with the development of livestock and poultry breeding and the implementation of national environmental protection policies, more and more scholars have invested in the research on recovery and reuse of livestock manure and turning waste into treasure (Zhang et al., 2015; Zhang, 2018; Menkem et al., 2018). In this study, considering many environmental problems in solid waste treatment and resource utilization in the livestock and poultry farming in Liaoning Province, we conducted experiments in a farm near Shenyang Aerospace University, Shenyang, Liaoning Province to study such problems. A 30-day static aerobic composting experiment with cow manure, pig manure, and chicken manure as composting raw 
materials and straw as a leavening agent was conducted to analyze variations of total nitrogen (TN), ammonia nitrogen (AN), total phosphorus (TP), active phosphorus (AP), total potassium (TK), and active potassium (AK) in different livestock manure composting aiming at providing a data basis and theoretical basis for the recycling and reduction of livestock manure compost.

\section{Materials and methods}

\section{Experimental material}

Three kinds of fresh manure used in the composting experiments with livestock manures were procured from the breeding farm near Shenyang Aerospace University in Shenbei New District, Shenyang, Liaoning, China. Corn stalks were cut into pieces of $2-4 \mathrm{~cm}$ by the knife mill before use. The information of composting materials is shown in Table 1.

Table 1. Parameters information of different compost materials

\begin{tabular}{c|c|c|c|c|c|c|c}
\hline Raw materials & $\begin{array}{c}\text { Water } \\
\text { content } \\
(\boldsymbol{\%})\end{array}$ & $\mathbf{p H}$ & $\begin{array}{c}\text { Total } \\
\mathbf{c a r b o n} \\
(\boldsymbol{\%})\end{array}$ & $\begin{array}{c}\text { Total } \\
\text { nitrogen } \\
(\boldsymbol{\%})\end{array}$ & $\begin{array}{c}\text { Total } \\
\mathbf{p o t a s s i u m} \\
\left(\mathbf{K}_{\mathbf{2}} \mathbf{O} \%\right)\end{array}$ & $\begin{array}{c}\text { Total } \\
\text { phosphorus } \\
\left(\mathbf{P}_{2} \mathbf{O}_{\mathbf{5}} \%\right)\end{array}$ & $\mathbf{C / N}$ \\
\hline Cattle manure & 68.9 & 7.64 & 38.32 & 1.78 & 1.48 & 1.45 & 21.53 \\
Pig manure & 73.4 & 7.35 & 39.41 & 1.80 & 1.58 & 1.78 & 21.89 \\
Chicken manure & 70.8 & 7.28 & 41.15 & 2.99 & 1.52 & 2.98 & 13.76 \\
Corn stalk & 21.5 & 7.19 & 54.82 & 1.04 & 0.98 & 0.46 & 52.71 \\
\hline
\end{tabular}

\section{Experimental apparatus}

The self-designed aerobic bioreactor was used in laboratory. The experiment photo and apparatus of the composting is shown in Figure 1.

\section{Experimental scheme}

An aerobic static composting was conducted using the composting materials of three livestock manures, including cattle manure (R1), pig manure (R2) and chicken manure (R3). The $30 \mathrm{~d}$ composting reaction was conducted with 6 self-designed aerobic composting boxes among which 2 composing boxes were considered as a group to contain single type of livestock manure.

In the whole composting process, different parameters like temperature, oxygen concentration, carbon dioxide concentration, density, etc. were monitored. Besides, the stink gas produced during the composting process was treated using a bio-filter. The change in every parameter in the composting process was compared and the changing law of the pile nutrient (the content of C-N-P-K) in the composing process with different livestock manures, humus and free humus were mainly analyzed.

Temperature was measured by thermometer. Oxygen concentration was measured by gas analyzer. 


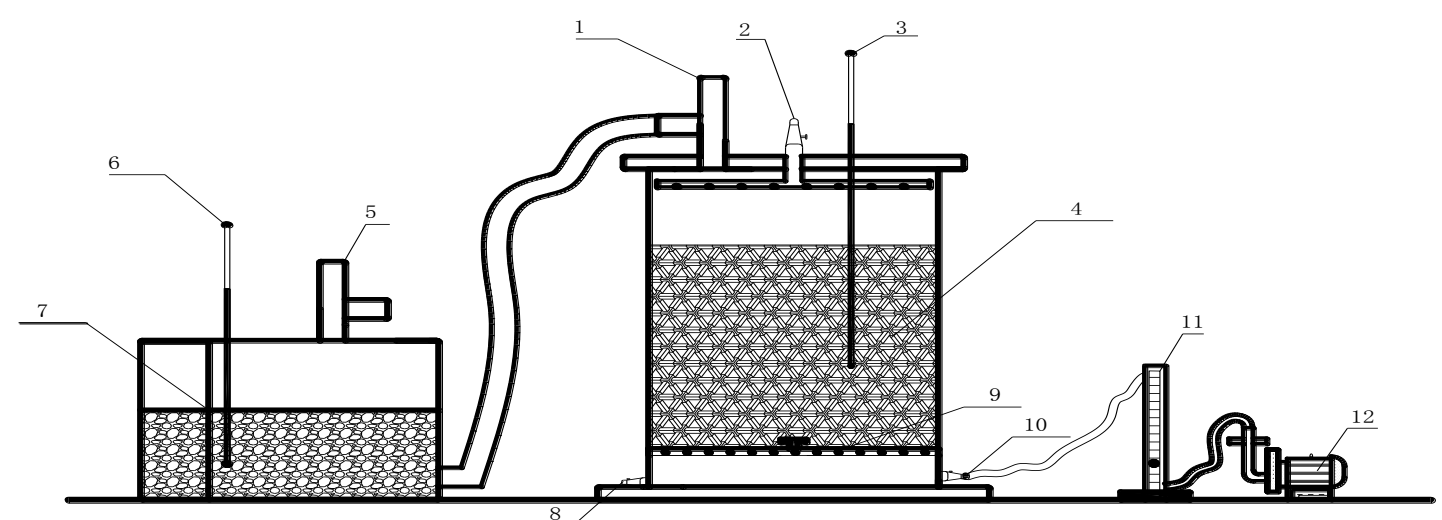

1. Vent of the composting box 2. Back-ejecta nozzle of leachate 3. Thermometer 4. Composting box 5. Gas outlet of bio-filter 6. Thermometer 7. Bio-filter 8. Discharge pipe of leachate 9. Grid plate 10. Inlet pipe 11. Flow meter 12. Fan

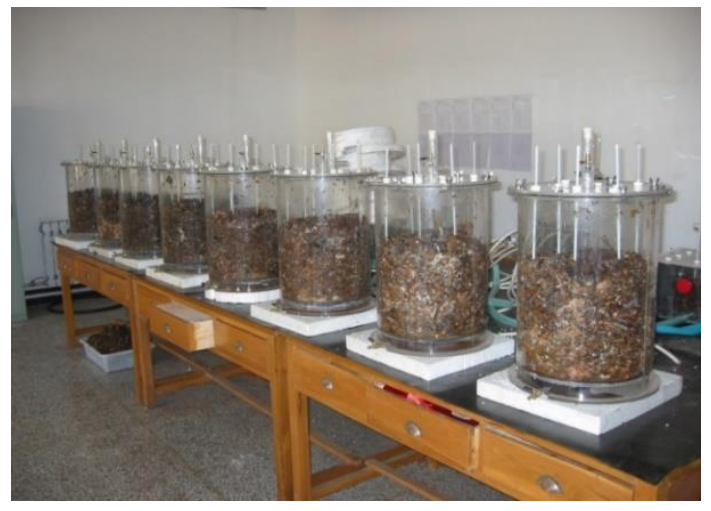

Figure 1. Experimental photo and apparatus used in the aerobic composting with livestock manures

\section{Sample collection and preparation}

The collection and conservation of the composting sample

The sampling method was the mixing of multiple sites. The same amount of sample from the upper layer, the middle layer and the lower layer of the composting were extracted and mixed thoroughly. Fresh composting sample were determined directly or put into $4^{\circ} \mathrm{C}$ refrigerator for further determination of indexes such as the water content, $\mathrm{pH}$, the conductivity (Petrie et al., 2015; Altenburger et al., 2015; Gou et al., 2018).

\section{The preparation of the composting water extracts}

Fresh sample which corresponded to $20 \mathrm{~g}$ dry sample was sampled and mixed with distilled water according to the weight ratio of 1:10 between sample and distilled water. Then it was oscillated for $32 \mathrm{~h}$ at the constant temperature of $26^{\circ} \mathrm{C}$ in the constant temperature oscillator and centrifuged for $20 \mathrm{~min}$ at $2000 \mathrm{rpm}$. The upper supernatant was preserved or determined (Wu et al., 2018).

\section{The preparation of air-dried composting sample}

A certain amount of the composting sample was put on the clean tray, dried for several days in the fume hood as well as grinded and filtered by 100 mesh (Liu et al., 2012). 


\section{Analytical methods}

\section{Total nitrogen}

The TN content in the sample was measured with the Kjeldahl method:

Select a $100 \mathrm{~mL}$ Kjeldahl bottle, accurately weigh $0.1 \mathrm{~g}$ of dry sample with an electronic balance, and add about $2 \mathrm{~g}$ of mixed catalyst, and transfer $3 \mathrm{~mL}$ of concentrated sulfuric acid with a pipette gun to the reagent bottle under slow shaking in the same direction, and then seal. Place the Erlenmeyer flask under the receiving tube of the condenser and insert the nozzle into the boric acid solution. Add $40 \mathrm{~mL}$ of $10 \mathrm{~mol} \cdot \mathrm{L}^{-1}$ sodium hydroxide solution to the distiller and close the distillation chamber for distillation. When the distillate reaches $30-40 \mathrm{~mL}$, stop the distillation. Then titrate with $0.02 \mathrm{~mol} \cdot \mathrm{L}^{-1}$ sulfuric acid standard solution until the solution is purple-red (Li et al., 2004; Cai et al., 2016).

\section{Ammonia nitrogen}

The AN content was measured with the Nessler's reagent spectrophotometry method:

First, take $2 \mathrm{~mL}$ of the digestive fluid into a $100 \mathrm{~mL}$ measuring cylinder and dilute to $100 \mathrm{~mL}$. Filter the diluted sample with a suction filter, and withdraw $50 \mathrm{~mL}$ of the clear solution and then place it in a $50 \mathrm{~mL}$ colorimetric tube. Then add in sequence $0.5 \mathrm{~mL}$ of analyzed sodium thiosulfate solution at a concentration of $3.5 \mathrm{~g} \cdot \mathrm{L}^{-1}, 0.5 \mathrm{~mL}$ of analytically pure zinc sulfate solution at a concentration of $100 \mathrm{~g} \cdot \mathrm{L}^{-1}, 4-5$ drops of analytically pure $\mathrm{NaOH}$ solution at a concentration of $2.5 \mathrm{~g} \cdot \mathrm{L}^{-1}$, and $0.5 \mathrm{~mL}$ of analytically pure potassium sodium tartrate solution at a concentration of $500 \mathrm{~g} \cdot \mathrm{L}^{-1}$ into the colorimetric tube. After adding $\mathrm{NaOH}$, flocculation and precipitation obviously occur, so let stand it for 10 minutes and wait for complete flocculation and precipitation. Sodium thiosulfate addition removes residual chlorine to eliminate interference with $\mathrm{Cl}^{-}$and results in $0.25 \mathrm{mg}$ removal of residual chlorine per $0.5 \mathrm{~mL}$ of the sodium thiosulfate solution. Take $10 \mathrm{~mL}$ of the sample from the lower part of the colorimetric tube with a pipette gun and place it into a $10 \mathrm{~mL}$ colorimetric tube. Wipe water stains on the surface of the colorimetric tube with lens cleaning paper, and put it into a multifunctional water quality detector. Measure the absorbance and AN concentration at a wavelength of $420 \mathrm{~nm}$ (Zhao, 2005).

\section{Total phosphorus}

Take $0.1 \mathrm{~g}$ of air-dried sample and screen it with a $0.5 \mathrm{~mm}$ sieve, place it into a flask, and rinse the inner wall of the flask with deionized water to reduce the error caused by a sample loss. At the same time, add $1.5 \mathrm{~mL}$ of $\mathrm{NaOH}$ solution $(30 \%)$ and $5.0 \mathrm{~mL}^{\circ} \mathrm{H}_{2} \mathrm{SO}_{4}$ solution to the reagent bottle, shake the reagent bottle slowly for mixing and then let it stand for 8 hours after mixing well. Add $0.25 \mathrm{~mL}$ of distilled water after the bottle is cooled to room temperature, then heat it again to boiling. Pipette $10 \mathrm{~mL}$ of the sample solution into a $50 \mathrm{~mL}$ volumetric flask, add water to $30 \mathrm{~mL}$, and check the color development. Make a color comparison and absorbance reading with a standard solution series under the same conditions. Select 7 volumetric flasks with suitable capacity and put $0,1.0,2.5,5.0,7.5,10.0,15.0 \mathrm{~mL}$ of phosphorus standard solution. Make up to $30 \mathrm{~mL}$ with distilled water, then add 2-3 drops of 2, 4-dinitrophenol solution to each volumetric flask with a pipette. Adjust with the $\mathrm{NaOH}$ solution and $\mathrm{H}_{2} \mathrm{SO}_{4}$ solution, and add $10 \mathrm{~mL}$ of ammonium vanadium molybdate reagent when the color of the solution changes to 
yellow, shake slowly and dilute to volume with distilled water. This solution is $1 \mathrm{~mL}$ containing phosphorus (Zhai, 2015; Wang et al., 2016).

\section{Active phosphorus}

The measurement of active phosphorus was done with the molybdenum-antimony anti-colorimetric method using $0.5 \mathrm{~mol} \cdot \mathrm{L}^{-1}$ sodium bicarbonate leachate. In acid soil, acidic ammonium salt is used to extract the active phosphorus to produce $\left(\mathrm{NH}_{4}\right)_{3} \mathrm{AlF}_{6}$ and $\left(\mathrm{NH}_{4}\right)_{3} \mathrm{FeF}_{6}$ complexes, while calcium ions generate a calcium fluoride precipitate, and $\mathrm{PO}_{4}{ }^{3-}$ ion is slowly released into the leaching solution (Wang, 2016).

\section{Data analysis}

Physicochemical parameters were determined in triplicate. Data were analyzed using One-way analysis of variance and multiple comparisons using the SPSS 18.0 software $(\mathrm{p}=0.05)$. All data figures were drawn using Origin 8.0. Significant differences in physicochemical parameter values between treatments and between experimental procedures were determined using least significance difference $(\mathrm{P}<0.05)(\mathrm{LSD})$.

\section{Results and discussion}

\section{Variations of $T N, A N$ in the experiments}

The organic nitrogen in the aerobic composting experiment goes through the processes of degradation, concentration, mineralization, and re-fixation, and the microbial flora converts mineral nitrogen into humus nitrogen through bioconcentration (Hall et al., 2015). Therefore, organic nitrogen is mainly distributed in different microbial flora and compost products of different humid levels during the composting process. This study focused on the changes in the TN and AN contents during the composting of the three kinds of livestock and poultry manures. Figure 2 shows the changes in TN content during the composting of livestock and poultry manures. The experimental results showed that in the initial stage of composting of livestock and poultry manures, the TN content of the piles R2 > R3 > R1 was $1.57 \% \pm 0.11 \%, 1.41 \% \pm 0.08 \%$, and $1.28 \% \pm 0.18 \%$, respectively. As the composting reaction progressed, the percentages of $\mathrm{TN}$ in the compost pile of livestock and poultry manures all showed an upward trend. When the experiments finished, the TN content in R2 was the highest at $2.25 \% \pm 0.18 \%$ and that in R3 and R1 was $2.14 \% \pm 0.15 \%$ and $1.93 \% \pm 0.18 \%$, respectively. The demand for organic carbon by microorganisms was higher than that for organic nitrogen, the general demand ratio being $\mathrm{C}: \mathrm{N}=25: 1$. During the process of composting degradation, the degradation rate of organic carbon was higher than that of organic nitrogen, leading to a lower rate of organic nitrogen loss during composting compared with that of organic carbon. Therefore, the percentages of TN in livestock and poultry manures compost piles all showed an upward trend. After the composting process, the TN content of $\mathrm{R} 1, \mathrm{R} 2$, and $\mathrm{R} 3$ compost piles all increased by $50.78 \%, 43.33 \%$, and $51.77 \%$, respectively. Among them, R3 had the largest increase, while R2 had the smallest. After composting, the nitrogen element was mainly composed of organic nitrogen. Nitrogen assimilation and fixation effect were obvious when poultry manure containing more mineral nitrogen was used for high-temperature composting, which was conducive to nitrogen storage and fertility retention (Hua et al., 2012; Zhang, 2014). 


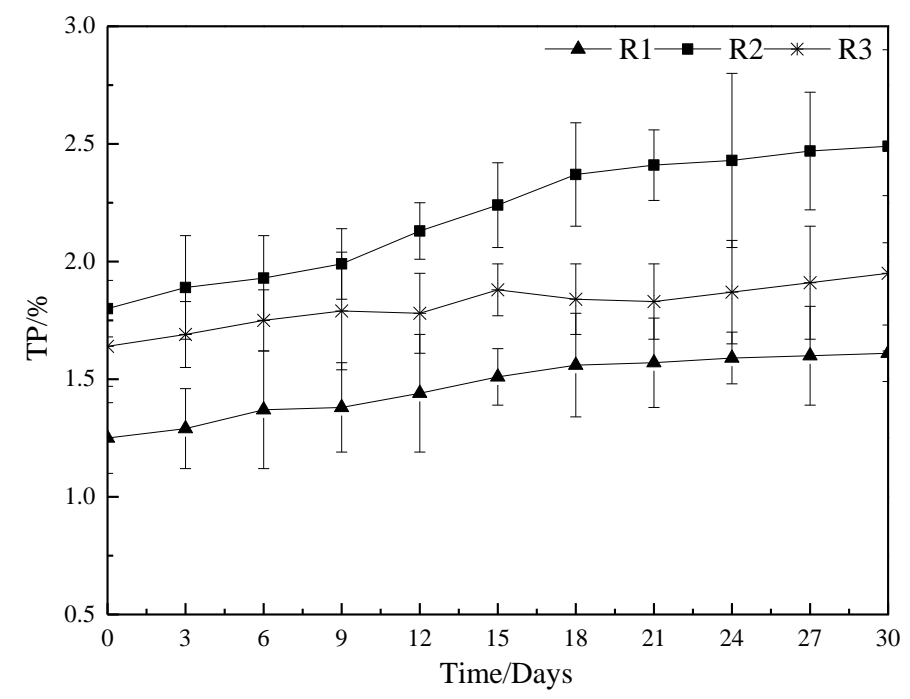

Figure 2. Changes in TN content during experiments

Figure 3 represents the change trend in the percentage of $\mathrm{AN}$ in $\mathrm{TN}$ during the composting process of livestock and poultry manures. The results showed that during the 30-day composting process, the percentage of $\mathrm{AN}$ in TN in the three types of livestock and poultry manure piles all increased first and then decreased. At the beginning of the composting reaction ( 0 days), the percentage of $\mathrm{AN}$ in the three manure compost piles of R1, R2, and R3 was 16.34, 15.28, and 15.97, respectively. After 3 days, AN accounted for the highest percentage in TN, which was $19.1,20.08$, and $21.14 \%$, respectively. With the progress in composting, the percentage of $\mathrm{AN}$ in TN in the pile showed a downward trend. When the experiments finished, the percentage of AN in TN became the highest, being 7.38, 8.11, and 9.22, respectively. Therefore, the percentage of AN in TN in the three types of livestock and poultry manure piles increased first and then decreased, mainly because nitrogen in livestock and poultry manures was divided into inorganic and organic states. Among them, organic nitrogen accounted for a large percentage, but it could not be stably presented in the manures, and it was easily decomposed into ammonia. During the 0-3 days of the composting process, the livestock and poultry manures were rich in proteins, which was decomposed under the action of microorganisms to form amino acids or amide compounds or to finally form inorganic ammonium salts. Therefore, the AN content in TN in the three kinds of livestock and poultry manures increased during the composting process from 0 to 3 days. It showed a downward trend during the composting process from 4 to 30 days. This was because, as the temperature and the $\mathrm{pH}$ value increased, $\mathrm{AN}$, mainly $\mathrm{NH}_{3}$ in the pile, was volatilized, reducing the $\mathrm{AN}$ content (Marhuenda-Egea et al., 2007; Awasthi et al., 2016). TN also dropped rapidly at this stage, but the decrease in AN was slightly greater than that in TN. Meanwhile, the hightemperature phase of the compost had passed, and the temperature of the pile had fallen. At this stage, humification was the primary factor, and mineralization was secondary. Most of the ammonium nitrogen was absorbed and utilized by the microorganisms and converted into humic acid nitrogen. On the contrary, with the enhancement of humification, the conversion of relatively simple acid-decomposed ammonium nitrogen into relatively complex other acid-decomposed nitrogen and non-acid-decomposed nitrogen resulted in a reduction in its quantity. 


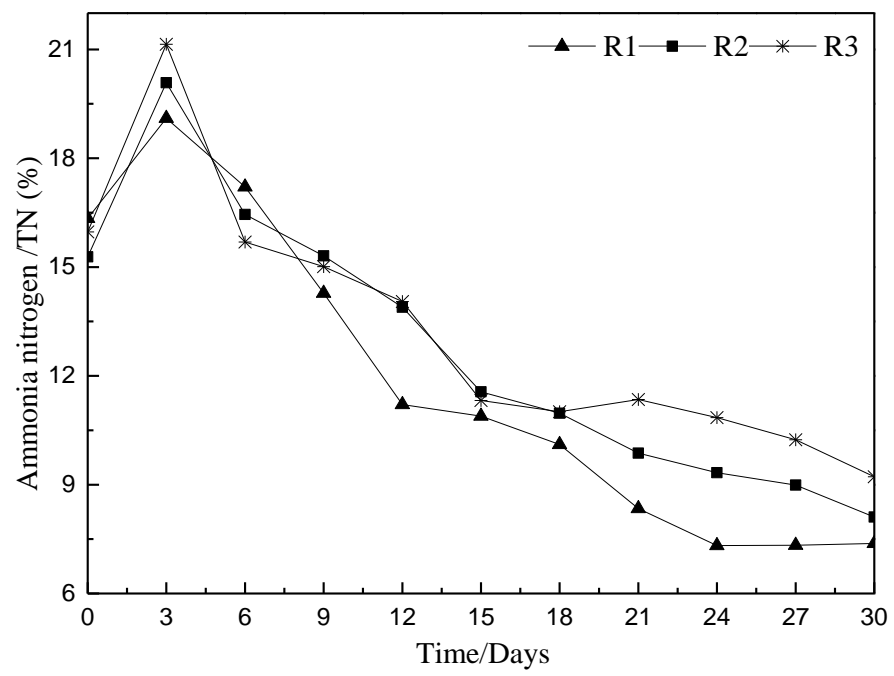

Figure 3. $A N$ as a percentage of $T N$ during experiments

The increase in humus retention of $\mathrm{NH}_{4}{ }^{+}$during humification was also one of the reasons for the decrease in AN/TN (Paradelo et al., 2013). Although the percentage of $\mathrm{AN}$ in TN of different livestock and poultry manures changed in the same way, at the end of composting, the percentage of $\mathrm{AN}$ in $\mathrm{TN}$ was different compared with that at the beginning, where R3 had the highest percentage, being 9.22. This was mainly because, compared with R1, R2, and R3, composting using R3 as raw material was conducive to the formation of ammonium nitrogen (Rajeshkumar et al., 2017).

\section{Variations of TP, AP in the composting of livestock manure}

Figure 4 shows the changes of TP content during the composting of different livestock and poultry manures. The experimental results show that the TP content in the compost heaps decreased from R2 > R3 > R1 at the initial stage of composting of livestock and poultry manures to a value of $1.80 \pm 0.12,1.64 \pm 0.17$, and $1.25 \pm 0.15 \%$, respectively. As the composting reaction progressed, the percentage of TP in livestock manure compost heaps increased which was mainly due to organic carbon, organic nitrogen, and organic phosphorus absorption, assimilation, and decomposition by microorganisms in the process of livestock manure composting. Demand for organic carbon by microorganisms is higher than demand for organic nitrogen and also for organic phosphorus with a general demand ratio of $\mathrm{C}: \mathrm{N}: \mathrm{P}=100: 5: 1$ (Santos et al., 2009). After the composting, the TP content in all three livestock manure (R1, R2, and R3) composting products increased to a value of $25.61,33.38$, and $11.58 \%$, respectively. During the experiments, $10 \%$ straw was selected as an additive to adjust the water content and void ratio. A reasonable material ratio promotes smooth progress of composting without a leachate and phosphorus loss in the whole process. Unlike nitrogen, which easily evaporates as a gas, phosphorus is stable which causes the smaller volatilization loss of the compost TP content (Villasenor et al., 2011; Singh et al., 2013). Besides, organic matter is decomposed and mineralized during the composting of livestock and poultry manure, and the dry matter content in the compost heaps reduces. So, the concentration of TP per unit mass of compost products from the three livestock manures increased. 


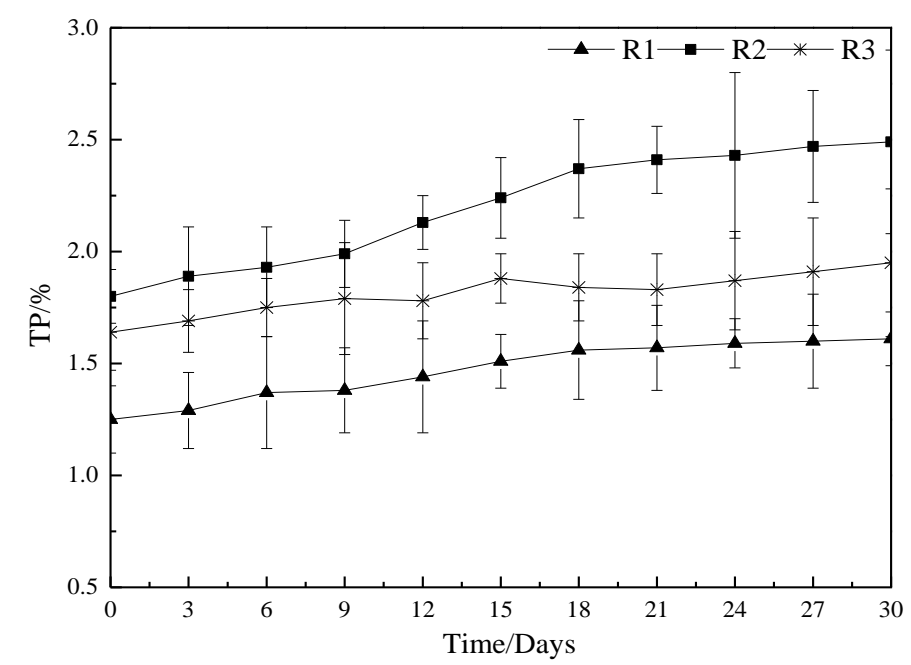

Figure 4. Changes of TP content during experiments

Figure 5 shows the changes of AP as a percentage of TP content during composting of livestock and poultry manures. The results show that the fractions of AP in TP in the three kinds of livestock manure compost heaps increased during the 30-day composting. At the beginning of the composting $(0 \mathrm{~d})$, the percentage of AP in the three compost heaps of R1, R2, and R3 was $18.31 \pm 1.25,24.8 \pm 1.15$, and $25.33 \pm 2.21 \%$, respectively. With the progress of composting, the percentage of AP in TP gradually increased, when the experiments finished, the percentage of AP in TP reached $24.15 \pm 1.97,29.33 \pm 3.34$, $34.33 \pm 1.58 \%$ and increased by $31.89,18.26$, and $35.53 \%$, respectively.

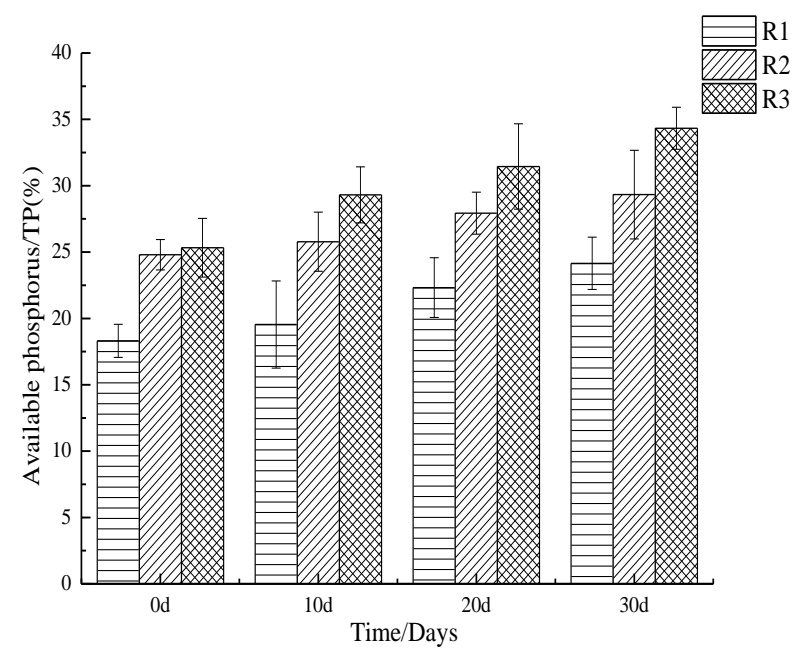

Figure 5. Changes of the percentage of AP in TP during experiments

\section{Variations of TK, AK in the composting of livestock manure}

Figure 6 shows the changes of TK content during the composting of different livestock and poultry manures. The experimental results show that the TK content in the compost heaps decreased from R3 $>$ R1 $>$ R2 at the initial stage of composting of livestock and poultry manures to a value of $1.21 \pm 0.12,1.14 \pm 0.12$, and $1.03 \pm 0.22 \%$, respectively. 
As the composting reaction progressed, the percentage of TK in livestock manure compost heaps increased and reached $1.61 \pm 0.22,1.72 \pm 0.3$, and $1.85 \pm 0.35 \%$, respectively, when the experiments finished. These increasing trends are mainly due to assimilation and decomposition of organic carbon, organic nitrogen, and organic phosphorus by microorganisms during the composting of livestock and poultry manure with a lower utilization rate of potassium than that of organic carbon, nitrogen, and phosphorus by microorganisms and basically no loss of potassium during composting.

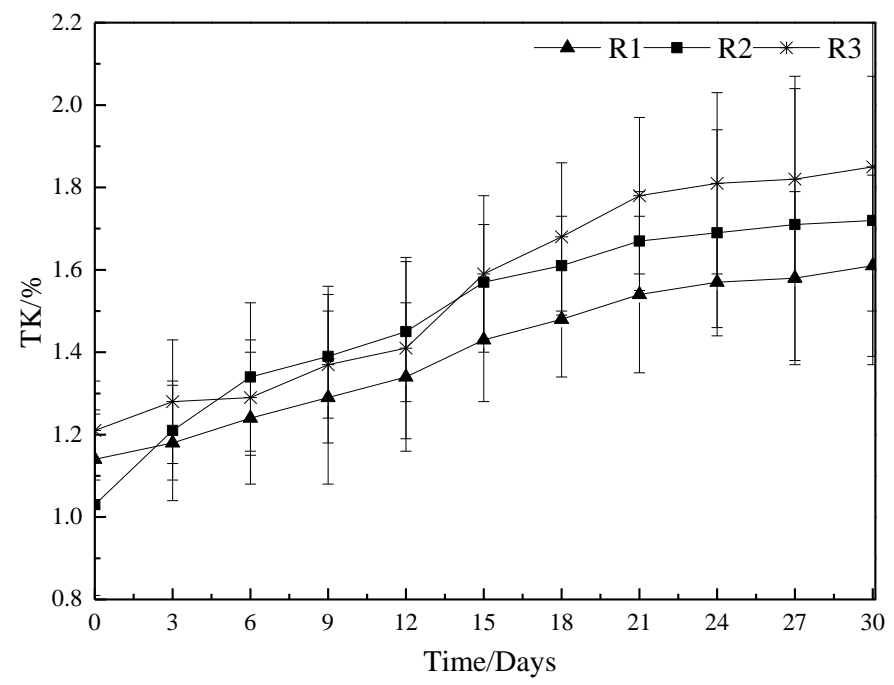

Figure 6. Changes of TK content during composting of livestock and poultry manure

Figure 7 shows the changes of fractions of AK in the TK content during composting of livestock and poultry manure. The results show that the fractions of AK in TK in the three kinds of livestock manure compost heaps increased during the 30-day composting. At the beginning of the composting ( 0 day), the percentage of $\mathrm{AK}$ in the three compost heaps of R1, R2, and R3 was $37.33 \pm 2.28,43.22 \pm 2.89$, and $44.21 \pm 2.15 \%$, respectively. With the progress of composting, the percentage of AP in TP gradually increased, and at the end of composting (30 days), the percentage of AP in TP reached $24.15 \pm 1.97$, $29.33 \pm 3.34,34.33 \pm 1.58 \%$ and increased by $31.89,18.26$, and $35.53 \%$, respectively. As the composting progressed, the fractions of AK in TK gradually increased and reached $49.44 \pm 2.74,58.37 \pm 2.21$, and $64.25 \pm 3.56 \%$ and increased by $31.89,18.26$, and $35.53 \%$, respectively, at the end of composting.

\section{Changes of total nutrients in the composting of livestock manure}

The total nutrient content in compost products is an important indicator of organic fertilizer quality (Santos et al., 2009) which is generally represented by the sum of N, P, and $\mathrm{K}$ elements where the element $\mathrm{N}$ is calculated as $\mathrm{TN}$, the element $\mathrm{P}$ is calculated as the $\mathrm{P}_{2} \mathrm{O}_{5}$ content, and the element $\mathrm{K}$ is calculated as the $\mathrm{K}_{2} \mathrm{O}$ content. There are three transformation forms for the conventional element $\mathrm{N}$ in the process of composting. The first is that nitrogen is converted into $\mathrm{NH}_{3}$ and exits the heap as exhaust gas during the composting, resulting in the loss of nitrogen fertilizer (Wang et al., 2013). The second is that nitrogen is used by nitrifying bacteria or nitrosating bacteria for nitrification reactions to form $\mathrm{NO}^{3-}$ or $\mathrm{NO}^{2-}$ during the composting. The third is that nitrogen is absorbed by 
microorganisms and converted into organic nitrogen (Wei et al., 2016). There are two transformation forms for the element $\mathrm{P}$ in the composting. One is that phosphorus is converted into $\mathrm{PH}_{3}$ and exits the heaps as exhaust gas during the composting, or a leachate is produced during the composting, resulting in the loss of phosphate fertilizer. But the loss rate is low compared to that of nitrogen (Zhang et al., 2017). The other is assimilation of phosphorus element by microorganisms into organic phosphorus which is also the main reason for enriched phosphorus in compost products. Transformation of K element is only microorganism absorption and utilization in the composting, and finally it exists in compost products. The total nutrients $\left(\mathrm{N}+\mathrm{P}_{2} \mathrm{O}_{5}+\mathrm{K}_{2} \mathrm{O}\right)$ content showed a rising trend in the composting of livestock and poultry manure due to the assimilation absorption and dissimilation decomposition of organic carbon, organic nitrogen, and organic phosphorus by microorganisms. Total experiments, the degradation rate of organic carbon is higher than that of organic nitrogen and organic phosphorus, and potassium is basically not lost. The loss of carbon and water causes a concentration effect (Wei et al., 2012) which increases the content of total nutrients (Liu et al., 2010). As shown in Table 2, pig manure compost had the highest total nutrient content of $6.33 \%$, and cow manure compost had the lowest total nutrient content of $5.04 \%$ at the end of composting.

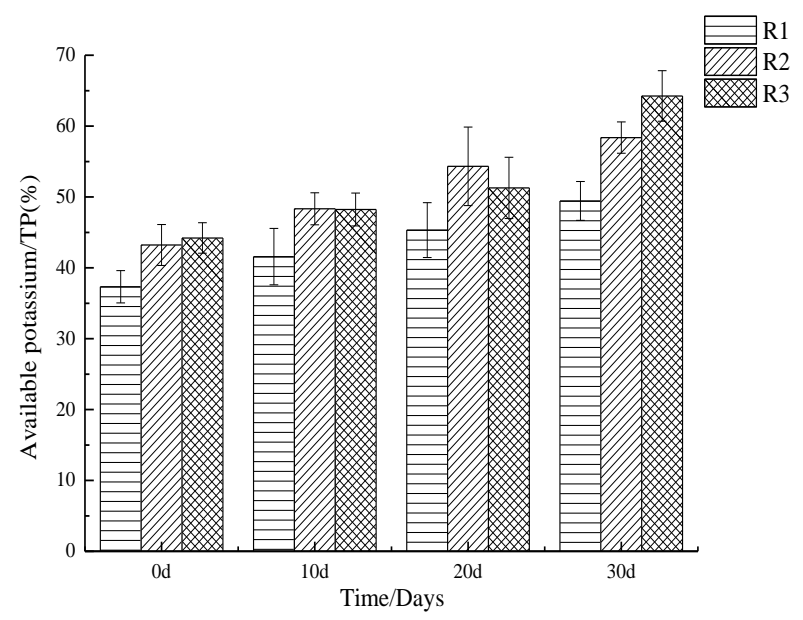

Figure 7. Changes of the percentage of $A K$ in TK during composting of livestock and poultry manure

According to the Organic Fertilizer Industry Standard (NY525-2012) published in 2012, qualified products should meet conditions that the mass fraction of organic matter is $\geq 45 \%$, the mass fraction of total nutrients $\left(\mathrm{N}+\mathrm{P}_{2} \mathrm{O}_{5}+\mathrm{K}_{2} \mathrm{O}\right)$ is $\geq 5 \%$, the water mass fraction is $\leq 30 \%$, and $\mathrm{pH}$ is in a range of 5.5-8.5. It can be seen from Table 2 that the nutrients of the three compost products reached the national standard (Zhou et al., 2014).

Table 2. Total nutrient content in livestock manure compost products

\begin{tabular}{c|c|c|c|c}
\hline Compost products & TN/\% & $\mathbf{T P} / \%$ & $\mathbf{T K} / \%$ & $\left(\mathbf{N}+\mathbf{P}_{2} \mathbf{O}_{\mathbf{5}}+\mathbf{K}_{\mathbf{2}} \mathbf{O}\right) / \%$ \\
\hline R1 & $1.93 \pm 0.18$ & $1.57 \pm 0.19$ & $1.54 \pm 0.19$ & 5.04 \\
R2 & $2.25 \pm 0.18$ & $2.41 \pm 0.15$ & $1.67 \pm 0.12$ & 6.33 \\
R3 & $2.14 \pm 0.15$ & $1.83 \pm 0.16$ & $1.78 \pm 0.19$ & 5.75 \\
\hline
\end{tabular}




\section{Conclusions}

Based on the 30-day static aerobic composting experiment with cow manure, pig manure, and chicken manure, we observed the variations of TN, AN, TP, AP, TK, and AK. It was shown that at the initial stage of composting, the TN content in the heaps decreased from $\mathrm{R} 2>\mathrm{R} 3>\mathrm{R} 1$ to a value of $1.57 \pm 0.11,1.41 \pm 0.08$, and $1.28 \pm 0.18 \%$, respectively. As the composting reaction proceeded, TN increased and reached the peak with the highest value of $2.25 \pm 0.18 \%$ for R2. The fractions of AN in TN increased first and then declined. At the end of composting (30 days), the fraction of AN in TN for R1, $\mathrm{R} 2$, and $\mathrm{R} 3$ reached the highest percentage of $7.38,8.11$, and $9.22 \%$, respectively. The TP content in all three manure compost heaps $(\mathrm{R} 1, \mathrm{R} 2, \mathrm{R} 3)$ showed an upward trend, and the increase was $25.61,33.38$, and $11.58 \%$, respectively. The fractions of AP in TP also showed increasing trends during the composting. At the end of composting ( 30 days), the fraction of AP in TP reached $24.15 \pm 1.97,29.33 \pm 3.34$, and $34.33 \pm 1.58 \%$ with an increase of $31.89,18.26$, and $35.53 \%$, respectively. The TK content in the compost heaps showed an increasing trend during the composting and reached $1.61 \pm 0.22,1.72 \pm 0.35$, and $1.85 \pm 0.35 \%$, respectively, when the experiments finished. The fraction of AK in TK for R1, R2, and R3 also showed increasing trends and reached the highest value of $49.44 \pm 2.74,58.37 \pm 2.21$, and $64.25 \pm 3.56 \%$ with an increase of $32.44,35.05$, and $45.32 \%$, respectively, at the end of composting (30 days).

Acknowledgements. This work was funded by the Yianyou Youth Talent Lift Program of Lanzhou Jiaotong University, Funds for Youth Science Foundation Project of Lanzhou Jiaotong University (2020018) and the National Natural Science Foundation of China (No.51606090, No.51866008).

\section{REFERENCES}

[1] Altenburger, R., Ait-Aissa, S., Antczak, P., Backhaus, T., Barceló, D., Seiler, T.-B., Brion, F., Busch, W., Chipman, K., López de Alda, M., de Aragao Umbuzeiro, G., Escher, B. I., Falciani, F., Faust, M., Focks, A., Hilscherova, K., Hollender, J., Hollert, H., Brack, W. (2015): Future water quality monitoring Adapting tools to deal with mixtures of pollutants in water resource management. - Science of the Total Environment 512-513: 540-551.

[2] Awasthi, M. K., Wang, Q., Huang, H., Ren, X., Lahori, A. H., Mahar, A., Ali, A., Shen, F., Li, R., Zhang, Z. (2016): Influence of zeolite and lime as additives on greenhouse gas emissions and maturity evolution during sewage sludge composting. - Bioresource Technology 216: 172-181.

[3] Cai, H. Z., Ning, X. C., Wang, Q. (2016): Effects of alkaline solids on the conditioning and composting of sludge and the potential of the products to improve the soil. - Environmental Science 37(12): 4848-4856.

[4] Gou, M., Hu, H. W., Zhang, Y. J., Wang, J. T., Hayden, H., Tang, Y. Q., He, J. Z. (2018): Aerobic composting reduces antibiotic resistance genes in cattle manure and the resistome dissemination in agricultural soils. - Science of the Total Environment 612: 1300-1310.

[5] Hall, D. J. M., Bell, R. W. (2015): Biochar and Compost Increase Crop Yields but the Effect is Short Term on Sandplain Soils of Western Australia. - Pedosphere 25(5): 720728.

[6] Hua, L., Chen, Y., Wu, W. (2012): Impacts upon soil quality and plant growth of bamboo charcoal addition to composted sludge. - Environmental Technology 33(1): 61-68.

[7] Li, J. J., Hao, J. M., Zou, G. Y. (2004): Carbon and nitrogen circulation and humus characteristics of high-temperature composting. - Ecology and Environment 13(3): 332334. 
[8] Liu, X. Y., Jin, J. Y., Ren, T. Z., He, P. (2010): Potential of organic manures nutrient resources and their environmental risk in China. - Chinese Journal of Applied Ecology 21(8): 2092 -2098.

[9] Liu, J., Li, J. N., Wen, K. J. (2012): Dynamic Transformation of Organic Carbon Under Different Communist Community Conditions. - Northern Horticulture 24: 174-178.

[10] Marhuenda-Egea, F. C., Martínez-Sabater, E., Jordá, J., Moral, R., Bustamante, M. A., Paredes, C., Pérez-Murcia, M. D. (2007): Dissolved organic matter fractions formed during composting of winery and distillery residues: Evaluation of the process by fluorescence excitation-emission matrix. - Chemosphere 68(2): 301-309.

[11] Meng, X. H. (2014): Study on Prevention Problem of China Livestock Environmental Pollution. - Huazhong Agricultural University.

[12] Menkem, E. Z., Ngangom, B. L., Tamunjoh, S. S. A., Boyom, F. F. (2018): Antibiotic residues in food animals: Public health concern. - Acta Ecologica Sinica.

[13] Paradelo, R., Moldes, A. B., Barral, M. T. (2013): Evolution of organic matter during the mesophilic composting of lignocellulosic winery wastes. - Journal of Environmental Management 116(Complete): 18-26.

[14] Petrie, B., Barden, R., Kasprzyk-Hordern, B. (2015): A review on emerging contaminants in wastewaters and the environment: Current knowledge, understudied areas and recommendations for future monitoring. - Water Research 72: 3-27.

[15] Rajeshkumar, S., Liu, Y., Zhang, X., Ravikumar, B., Bai, G., Li, X. (2017): Studies on seasonal pollution of heavy metals in water, sediment, fish and oyster from the Meiliang Bay of Taihu Lake in China. - Chemosphere 191(4): 626.

[16] Santos, P. S. M., Duarte, R. M. B. O., Duarte, A. C. (2009): Absorption and fluorescence properties of rainwater during the cold season at a town in Western Portugal. - Journal of Atmospheric Chemistry 62(1): 45-57.

[17] Singh, J., Kalamdhad, A. S. (2013): Assessment of bioavailability and leachability of heavy metals during rotary drum composting of green waste (Water hyacinth). - Ecological Engineering 52(2): 59-69.

[18] Villasenor, J., Rodríguez, L., Fernández, F. J. (2011): Composting domestic sewage sludge with natural zeolites in a rotary drum reactor. - Bioresource Technology 102(2): 14471454.

[19] Wang, L., Zhang, Y., Lian, J., Chao, J., Gao, Y., Yang, F., Zhang, L. (2013): Impact of fly ash and phosphatic rock on metal stabilization and bioavailability during sewage sludge vermicomposting. - Bioresour Technol 136(5): 281-287.

[20] Wang, Y. F. (2016): Changes of Culturable Microorganisms, Humus Content and Enzyme Activities in Composting of Four Kinds of Livestock Dung. - Gansu Agricultural University.

[21] Wang, Y. X., Gao, L. F., Ye, J., Li, Y., Weng, B. (2016): Change of carbon substance characteristics during composting of waste packing and fungus chaff. - Transactions of the Chinese Society of Agricultural Engineering 32(s2): 292-296.

[22] Wei, Z., Zhao, X., Zhu, C., Xi, B., Zhao, Y., Yu, X. (2016): Assessment of humification degree of dissolved organic matter from different composts using fluorescence spectroscopy technology. - Chemosphere 95(1): 261-267.

[23] Wu, W., Sheng, H., Gu, C., Song, Y., Willbold, S., Qiao, Y., Liu, G., Zhao, W., Wang, Y., Jiang, X., Wang, F. (2018): Extraneous dissolved organic matter enhanced adsorption of dibutyl phthalate in soils: Insights from kinetics and isotherms. - Science of the Total Environment 631: 1495-1503.

[24] Zhai, Q. M. (2015): The Research about the Response of Farmland Animal Community to Pesticide and EM Compost Treatment. - Harbin Normal University.

[25] Zhang, Z. (2014): Nutrient transformation during aerobic composting of pig manure with biochar prepared at different temperatures. - Environmental Technology 36(7): 1-28.

[26] Zhang, Q. Q., Ying, G. G., Pan, C. G., Liu, Y. S., Zhao, J. L. (2015): Comprehensive evaluation of antibiotics emission and fate in the river basins of china: source analysis, 
multimedia modeling, and linkage to bacterial resistance. - Environmental Science \& Technology 49(11): 6772-6782.

[27] Zhang, C., Xu, Y., Zhao, M., Rong, H., Zhang, K. (2017): Influence of inoculating whiterot fungi on organic matter transformations and mobility of heavy metals in sewage sludge based composting. - Journal of Hazardous Materials 344: 163-168.

[28] Zhang, B. B. (2018): Assessment of Raw Material Supply Capability and Energy Potential of Biomass Resource in China. - China Agricultural University.

[29] Zhao, S. F. (2005): Study on the PhosPhorus during the Aerobie ComPosting Process. Zhejiang University.

[30] Zhou, Y., Selvam, A., Wong, J. W. C. (2014): Evaluation of humic substances during cocomposting of food waste, sawdust and Chinese medicinal herbal residues. - Bioresource Technology 168(3): 229-234.

[31] Zhu, J. C., Zhang, Z. Q., Fan, Z. M., Li, R. H. (2014): Biogas Potential, Cropland Load and Total Amount Control of Animal Manure in China. - Journal of Agro-Environment Science 33(3): 435-445. 